\title{
Low-dose dobutamine stress echocardiography cannot predict mitral regurgitation reversibility after coronary artery bypass grafting
}

\author{
Farideh Roshanali, MD, ${ }^{\mathrm{a}}$ Saeed Shoar, MD, ${ }^{\mathrm{a}, \mathrm{b}, \mathrm{c}}$ Nasrin Shoar, MD, ${ }^{\mathrm{d}}$ Mohammad Naderan, MD, ${ }^{\mathrm{c}}$ \\ Farshid Alaeddini, MD, PhD, ${ }^{\mathrm{a}}$ and Mohammad Hossein Mandegar, $\mathrm{MD}^{\mathrm{b}}$
}

\begin{abstract}
Background: The ideal management of ischemic mitral regurgitation (MR) remains a clinical dilemma because of the suboptimal available therapeutic options. Recently, new concepts have emerged, pointing to the benefits of a patient selection approach when debating the management of moderate ischemic MR. We investigated the predictability of low-dose dobutamine stress echocardiography (DSE) in selecting candidates for CABG with moderate MR for valve repair.
\end{abstract}

\begin{abstract}
Methods: From November 2002 to May 2010, 110 candidates for first-time CABG, who were admitted to the cardiac surgery department in Day General Hospital (Tehran, Iran), were enrolled in the present cross-sectional study. DSE was performed for each case before CABG. Those with positive findings underwent CABG alone and those with negative results underwent concomitant $\mathrm{CABG}$ and mitral valve repair. The patients were followed up for a minimum of 60 months.

Results: Of the 110 patients, $47(42.72 \%)$ had positive test results and underwent CABG alone and $63(57.28 \%)$ had negative DSE results and underwent concomitant CABG and mitral valve repair. The MR degree had decreased from $2.8 \pm 0.3$ preoperatively to $1.46 \pm 0.6$ early during the hospital stay and $1.9 \pm 0.7$ during late follow-up in the CABG group. It had decreased from $2.84 \pm 0.4$ preoperatively to $0.93 \pm 0.65$ postoperatively but then increased to $1.41 \pm 0.9$ during late follow-up, for a significant decrease in the combined group $(P<.05)$.
\end{abstract}

Conclusions: Despite its utility in selecting CABG patients with moderate ischemic MR for valve repair from a short-term perspective, the use of DSE cannot predict the long-term outcomes of these patients. (J Thorac Cardiovasc Surg 2014;148:1323-7)

Ischemic mitral regurgitation (IMR) occurs as a result of ischemia-induced mitral valve functional insufficiency. ${ }^{1,2}$ Despite advances in the management of IMR, it has proved to be adversely associated with survival, even in mild to moderate severity. ${ }^{2-5}$ In addition, the prevalence of IMR subsequent to myocardial infarction has been reported to be $20 \%$ to $40 \%{ }^{2,6,7}$ With the large number of patients experiencing myocardial infarction, IMR has continued to impose a huge burden on the healthcare system. . $^{2,7,8}$

The ideal management of IMR remains a clinical dilemma because of the suboptimal available therapeutic options. ${ }^{9-13}$ Because the long-term prognosis of uncorrected IMR has been documented to be poor, ${ }^{10,14}$ some investigators have

\footnotetext{
From the Departments of Cardiology ${ }^{\mathrm{a}}$ and Cardiac Surgery, ${ }^{\mathrm{b}}$ Day General Hospital, Tehran, Iran; Department of Surgery, ${ }^{c}$ Shariati Hospital, Tehran University of Medical Sciences, Tehran, Iran; and School of Medicine, ${ }^{\mathrm{d}}$ Kashan University of Medical Sciences, Kashan, Iran.

Disclosures: Authors have nothing to disclose with regard to commercial support.

Received for publication July 23, 2012; revisions received Oct 20, 2013; accepted for publication Dec 23, 2013; available ahead of print Feb 8, 2014.

Address for reprints: Saeed Shoar, MD, Departments of Cardiology and Cardiac Surgery, Day General Hospital, No. 1434873111, Tavanir St, Vali e Asr Ave, Tehran, Iran (E-mail: ssht84@yahoo.com).

$0022-5223 / \$ 36.00$

Copyright () 2014 by The American Association for Thoracic Surgery

http://dx.doi.org/10.1016/j.jtcvs.2013.12.028
}

proposed surgical correction of IMR, using either repair or replacement, concurrent with coronary artery bypass grafting $(\mathrm{CABG}) .^{10,12,15-18}$ However, the greater morbidity and mortality of a combined approach has kept surgeons from widely performing such a correction technique for moderate IMR. ${ }^{4,19-23}$

Recently, attention has been given to a selection approach in the management of simultaneous coronary artery diseases and moderate IMR. ${ }^{1,24,25}$ The selective approach is used preoperatively to measure the probability of IMR reversibility after $\mathrm{CABG}{ }^{26,27}$

To determine which patient with moderate IMR will benefit from intervening on the mitral valve and which patient should undergo CABG alone, we previously reported on the valuable utility of low-dose dobutamine stress echocardiography (DSE) in selecting patients who would be undergoing CABG to receive concurrent mitral valve repair. ${ }^{26}$ In a continuation of that study, we investigated the benefits of DSE in predicting the long-term outcomes.

\section{METHODS \\ Study Population}

From November 2002 to May 2010, 110 candidates for first-time CABG, who had been admitted to the cardiac surgery department in Day General Hospital (Tehran, Iran), were consecutively enrolled in the present cross-sectional study. The inclusion criteria were candidacy for CABG and 


$$
\begin{aligned}
& \text { Abbreviations and Acronyms } \\
& \begin{aligned}
\text { CABG } & =\text { coronary artery bypass grafting } \\
\text { DSE } & =\text { dobutamine stress echocardiography } \\
\text { EF } & =\text { ejection fraction } \\
\text { IMR } & =\text { ischemic mitral regurgitation } \\
\text { MR } & =\text { mitral regurgitation }
\end{aligned}
\end{aligned}
$$

the presence of grade 2 and 3 (referred to as moderate) functional MR on a scale of 1 to 4 , using quantitative echocardiography, measured by 2 independent cardiologists, who were unaware of the study protocol. Patients with structural MR, including a ruptured chordae tendinea or papillary muscle, abnormal leaflet thickening, annular calcification, and ventricular aneurysms or other congenital or acquired valvular diseases, and those considered for other concomitant surgical procedures were excluded from the present study.

The institutional review board of Day General Hospital approved the study protocol on human subjects, and each patient provided informed consent before enrollment in the present study.

\section{Dobutamine Stress Echocardiography}

Dobutamine was infused at doses of $2.5,5.0,7.5$, and $10.0 \mu \mathrm{g} / \mathrm{kg} / \mathrm{min}$ after the echocardiogram at rest was finished. The patients were closely monitored by their physician during the dobutamine infusion for any symptoms of distress. The DSE findings were considered positive if echocardiographic MR had decreased in response to the dobutamine infusion and negative if the degree of MR had remained unchanged or had increased.

DSE-positive patients were assigned to the CABG-alone group, with no additional procedure on the valves. The DSE-negative patients underwent concomitant $\mathrm{CABG}$ and mitral valve repair.

\section{Preoperative Echocardiography}

The patients underwent the echocardiographic assessment in a left lateral decubitus position with a multifrequency phased-array probe (VIVID 7, GE Medical Systems, Little Chalfont, UK; and iE33, Philips Medical Systems, Best, The Netherlands) before and after dobutamine infusion in an at rest and stress status, respectively, to assess the myocardial viability and severity of MR. The instrument settings were kept constant during all echocardiographic studies. The settings included the rate of pulse repetition, transducer frequencies, and optimal gain. The optimal gain for intracardiac blood flow imaging and the detection of the extension area related to the regurgitant signals was adjusted to the level at which the background noise began to faintly appear.

The digital recording of each echocardiography was analyzed for segmental wall motion abnormality using the American Society of Echocardiography 16-segment convention by 2 independent observers who were unaware of the purpose of the study. The ejection fraction (EF) was measured using the modified biplane Simpson method. MR was graded using a combination of quantitative and qualitative variables, including color Doppler jet characteristics, width and area of the jet, continuous wave Doppler intensity, shape of the spectral recording, mitral inflow and evaluation of pulmonary vein flow, using the proximal isovelocity surface area method, and calculation of the effective regurgitant orifice area, regurgitant volume, and regurgitant fraction. Two independent observers reached a consensus in the analysis of all the recordings.

\section{Operation Technique}

The left internal mammary artery for the left anterior descending artery and a greater saphenous vein graft for other involved coronary arteries were harvested and distally anastomosed after a full midline sternotomy. The cardiopulmonary circulation was bypassed, along with preservation of the myocardium by administration of iced saline to provide topical and systemic hypothermia to $28^{\circ} \mathrm{C}$. According to the assigned treatment group, concomitant $\mathrm{CABG}$ and valve repair using complete ring annuloplasty was performed. The size of the mitral annuloplasty ring (Carpentier-Edwards Physio Ring; Edwards Life Sciences, Irving, Calif) was determined by a standard measurement of the intertrigonal distance and anterior leaflet height after downsizing was performed. Finally, intraoperative transesophageal echocardiography was performed to assess the severity of MR in the surgical patients.

\section{Postoperative Echocardiography}

The echocardiographic study was repeatedly performed for all patients 4 to 7 days and 5 to 6 months postoperatively and then annually to assess the EF, wall motion, and MR severity.

\section{Statistical Analysis}

The data were analyzed using the Statistical Package for Social Sciences, version 16 (SPSS, Chicago, Ill). The Student $t$ test was applied for a comparison of the clinical outcomes between the 2 groups. One-way repeated measurement analysis of variance was also used for the measurement of the within-subject effects for EF, MR, and New York Heart Association function class.

\section{RESULTS \\ Patients Characteristics}

A total of 110 patients were enrolled in our study. Of these 110 patients, $47(42.72 \%)$ had DSE-related MR improvement $(1 \pm 0.62)$ and underwent CABG alone and 63 patients $(57.28 \%)$ did not have DSE-related MR improvement $(0.14 \pm 0.2)$ and underwent concomitant CABG and mitral valve repair. The mean \pm standard deviation duration of follow-up was $81.5 \pm 17.7$ and $77.5 \pm 19.2$ months in CABG and combined groups, respectively. The demographics and primary characteristics of the study patients are listed in Table 1 . No significant difference was found between the 2 groups in terms of the primary characteristics $(P>.05)$.

\section{Echocardiographic Evaluation}

Regarding the echocardiographic features for the patients undergoing $\mathrm{CABG}$ or concomitant $\mathrm{CABG}$ and valve repair, the size of the annulus was $37.70 \pm 3.78 \mathrm{~mm}$ in group 1 and $37.30 \pm 3.97 \mathrm{~mm}$ in group 2, which was not a statistically significant difference $(P>.05)$. The effective regurgitant orifice area had a mean $\pm \mathrm{SD}$ of $28.83 \pm 5.57 \mathrm{~cm}^{2}$ in group 1 and $28.90 \pm 5.83 \mathrm{~cm}^{2}$ in group 2, with no significant differences $(P>.05)$. The mean $\pm \mathrm{SD}$ coaptation depth was measured at $7.77 \pm 1.02 \mathrm{~mm}$ in group 1 and $7.76 \pm 0.91$ $\mathrm{mm}$ in group 2, with no significant difference $(P>.05)$. In addition, the MR degree did not differ significantly $(P>.05)$ between groups 1 and 2 (mean \pm SD of $2.87 \pm 0.33$ and $2.84 \pm 0.36$, respectively). The EF for the 110 patients was a mean \pm SD of $39.04 \% \pm 5.95 \%$ in group 1 and $40.95 \% \pm 5.59 \%$ in group 2 . The difference was also not statistically significant $(P>.05)$. The left ventricular end-diastolic and end-systolic volume was $140.72 \pm 33.37 \mathrm{~mL}$ and $90.23 \pm 21.05 \mathrm{~mL}$ in group 1 
TABLE 1. Demographic and clinical patient characteristics

\begin{tabular}{lccc}
\hline \multicolumn{1}{c}{ Characteristic } & $\begin{array}{c}\text { CABG group } \\
(\mathbf{n}=\mathbf{4 8})\end{array}$ & $\begin{array}{c}\text { Combined group } \\
(\mathbf{n = 6 2})\end{array}$ & $\boldsymbol{P}$ valu \\
\hline Age (y) & $56.9 \pm 10.1$ & $58.4 \pm 9.3$ & .45 \\
Gender (n) & & & .15 \\
$\quad$ Male & 33 & 52 & \\
$\quad$ Female & 14 & 11 & .30 \\
Follow-up duration (mo) & $81.5 \pm 17.7$ & $77.5 \pm 19.2$ & .35 \\
DM (\%) & 36.2 & 27 & .20 \\
HLP (\%) & 68.1 & 58.7 & .50 \\
HTN (\%) & 53.2 & 46.0 & .10 \\
NYHA functional class & $2.87 \pm 0.6$ & $2.70 \pm 0.5$ & .70 \\
Graft vessel (n) & $3.2 \pm 1.2$ & $3.3 \pm 1.1$ & \\
\hline
\end{tabular}

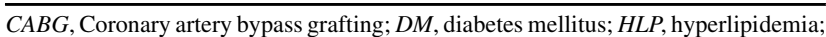
$H T N$, hypertension; NYHA, New York Heart Association.

and $139.21 \pm 29.62 \mathrm{~mL}$ and $90.29 \pm 21.90 \mathrm{~mL}$ in group 2, respectively, with no significant differences. The echocardiographic features of the patients before surgery are listed in Table 2.

\section{Follow-up Reassessment}

During the follow-up period, the patients were assessed at 3 intervals: preoperatively, early postoperatively, and later, at the end of the study period. At these intervals, the MR, $\mathrm{EF}$, and function class were assessed.

\section{MR Severity}

The MR severity decreased from $2.87 \pm 0.3$ preoperatively to $1.46 \pm 0.62$ at early postoperatively and $1.91 \pm 0.70$ at late follow-up for the patients in the CABG-alone group. The MR severity decreased from 2.84 \pm 0.36 preoperatively to $0.93 \pm 0.65$ at early postoperatively and $1.41 \pm 0.89$ at late follow-up in combined group. The decrease in MR severity was significantly greater in group 2 (combined group) than in group $1(\mathrm{CABG}$ alone; $P<.05)$.

\section{EF Improvement}

The EF was $39.04 \% \pm 5.95 \%$ preoperatively, $42.91 \% \pm$ $5.79 \%$ early postoperatively, and $43.93 \% \pm 6.10 \%$ at late

TABLE 2. Comparison of echocardiographic parameters between groups

\begin{tabular}{lccc}
\hline \multicolumn{1}{c}{ Variable } & $\begin{array}{c}\text { CABG group } \\
(\mathbf{n = 4 8})\end{array}$ & $\begin{array}{c}\text { Combined group } \\
(\mathbf{n = 6 2})\end{array}$ & $\boldsymbol{P}$ value \\
\hline Annulus size $(\mathrm{mm})$ & $37.7 \pm 3.8$ & $37.30 \pm 3.9$ & .60 \\
Effective regurgitant & $28.8 \pm 5.6$ & $28.90 \pm 5.9$ & .95 \\
$\quad$ orifice area $\left(\mathrm{cm}^{2}\right)$ & & & \\
Coaptation depth mm & $7.77 \pm 1$ & $7.76 \pm 0.9$ & .98 \\
MR (mean) & $2.87 \pm 0.3$ & $2.84 \pm 0.4$ & .65 \\
EF $(\%)$ & $39.04 \pm 5.9$ & $40.95 \pm 5.6$ & .10 \\
LVEDV (mL) & $140.72 \pm 33.4$ & $139.21 \pm 29.6$ & .80 \\
LVESV (mL) & $90.23 \pm 21$ & $90.29 \pm 21.9$ & .99 \\
Dobutamine-induced & $0.14 \pm 0.2$ & $1 \pm 0.62$ & $<.01$ \\
$\quad$ MR improvement & & & \\
\hline
\end{tabular}

Data presented as mean \pm standard deviation. $C A B G$, Coronary artery bypass grafting; $M R$, mitral regurgitation; $E F$, ejection fraction; $L V E D V$, left ventricular end-diastolic volume; $L V E S V$, left ventricular end-systolic volume. follow-up in group 1 and $40.95 \% \pm 5.59 \%$ preoperatively, $45.74 \% \pm 4.64 \%$ early postoperatively, and $48.10 \% \pm$ $3.60 \%$ at late follow-up in group 2 . The improvement was significantly better in group 1 than in group $2(P<.05)$.

\section{Improvement in Function Class}

The functional class in the group 1 patients changed from $2.87 \pm 0.61$ preoperatively to $1.38 \pm 0.49$ at late follow-up compared with a change from $2.70 \pm 0.55$ preoperatively to $1.41 \pm 0.53$ at late follow-up for group 2 . This difference was not statistically significant $(P>.05)$.

\section{DISCUSSION}

It has been well described that the reversibility of IMR depends on the underlying mechanism that has evoked the functional insufficiency of the mitral valve. ${ }^{13,28-30}$ If the disease has occurred because of rupture of a papillary muscle or chordae, the repair will result in improvement of valve function. ${ }^{12,16}$ However, IMR develops more probably as a result of ventricular dysfunction affected by impairment in the coronary artery circulation. ${ }^{1} \mathrm{By}$ a similar rational, it would be expected that IMR would resolve to some extent by improving the coronary artery perfusion to the ventricular myocardium. ${ }^{10}$

The surgical management of IMR comprises CABG alone for revascularization of the ischemic myocardium and mitral valve replacement or additional techniques of valve repair concomitant with CABG. ${ }^{1,21,23,24,31}$ In contrast to severe IMR for which concomitant $\mathrm{CABG}$ and valve procedures have been strongly advised, ${ }^{32}$ the optimal treatment of moderate IMR is still a source of debate. ${ }^{1,10,18,32,33}$ Currently, evidence supports an individualized approach in deciding the best treatment modality for each patient with moderate IMR. ${ }^{32,34}$ This selective approach mainly uses the extent of damage to the mitral valve due to ischemia. ${ }^{1,12,16}$ Depending on the modality used to determine the extent of the damage, patients could be selected more efficiently for concomitant valve procedures. ${ }^{27,35}$ Despite the utility of Doppler color flow imaging for patient selection of operative treatment of IMR, its long-term usefulness, especially in the case of moderate IMR, has not been documented. ${ }^{36,37}$ However, using preoperative and intraoperative echocardiography, mitral valve regurgitation could be accurately monitored and MR reversibility could be more reliably determined. ${ }^{26,27,35-38}$

We had previously reported on the beneficial utility of DSE in the preoperative prediction of IMR reversibility. ${ }^{26}$ In that study, we showed the predictability of IMR reversibility using DSE. However, the long-term survival and recurrence of $\mathrm{MR}$ in the patients with unrepaired moderate IMR who had undergone CABG alone without an additional valve procedure was unclear. In the present study, we continued monitoring our patients to determine whether 
TABLE 3. Comparison of outcomes between 2 groups

\begin{tabular}{lrrr}
\hline \multicolumn{1}{c}{ Variable } & $\begin{array}{c}\text { CABG group } \\
(\mathbf{n}=\mathbf{4 8})\end{array}$ & $\begin{array}{c}\text { Combined group } \\
(\mathbf{n}=\mathbf{6 2})\end{array}$ & $\boldsymbol{P \text { value }}$ \\
\hline MR (mean) & & & $<.0001$ \\
$\quad$ Preoperative & $2.87 \pm 0.3$ & $2.84 \pm 0.4$ & \\
$\quad$ Early follow-up & $1.46 \pm 0.6$ & $0.93 \pm 0.6$ & \\
$\quad$ Late follow-up & $1.91 \pm 0.7$ & $1.41 \pm 0.9$ & \\
EF (\%) & & & $<.0001$ \\
$\quad$ Preoperative & $39.04 \pm 5.9$ & $40.95 \pm 5.6$ & \\
$\quad$ Early follow-up & $42.91 \pm 5.8$ & $45.74 \pm 4.6$ & \\
$\quad$ Late follow-up & $43.93 \pm 6.1$ & $48.10 \pm 3.6$ & \\
NYHA functional class & & & .5 \\
$\quad$ Preoperative & $2.87 \pm 0.6$ & $2.70 \pm 0.5$ & \\
$\quad$ Early follow-up & $2.1 \pm 0.5$ & $1.9 \pm 0.4$ & \\
$\quad$ Late follow-up & $1.38 \pm 0.5$ & $1.41 \pm 0.5$ & \\
\hline D &
\end{tabular}

Data presented as mean \pm standard deviation. $C A B G$, Coronary artery bypass grafting; $M R$, mitral regurgitation; $E F$, ejection fraction; NYHA, New York Heart Association.

DSE would remain predictive after a longer follow-up period.

According to the results from the present study, the severity of MR decreased more significantly in patients undergoing concomitant valve repair and $\mathrm{CABG}$, although the improvement in EF was more remarkable among the patients undergoing CABG alone. However, the less desirable outcomes in both groups did not lead to readmission or reoperation for MR. Stratified by the DSE findings, the patients without MR improvement during the test (CABG group) were less likely to develop improvement in the EF and MR. However, their New York Heart Association score had resolved more significantly at the late follow-up assessment. In contrast, those patients who had undergone concomitant CABG and valve repair had better improvement in the $\mathrm{EF}$ and a more remarkable reversal of MR, although they showed less resolution of the New York Heart Association score at the late follow-up assessment. The differences between the 2 groups with respect to EF and MR severity were less substantial in the early follow-up period than in the late-term period (Table 3). Thus, despite the predictive value of DSE in the early postoperative period, as previously reported, ${ }^{26}$ its utility in predicting later outcomes is not definite. One reason for this could be the minimal difference in the EF and MR severity between the 2 groups that in the long term do not represent useful determining and predictive parameters. The MR degree in the $\mathrm{CABG}$ group might have improved even more if mitral repair had also been performed. Therefore, our data might suggest that mitral valve repair should be considered even with a positive viability test result, because it is possible that the outcomes might be improved even further. Moreover, the similar symptomatic status of both groups at an average of 6 years of follow-up could be misleading and could deteriorate later in the CABG-alone group with the observed poorer hemodynamic conditions.
Considering the limitations of our study, we would suggest application of 3-dimensional echocardiography and more quantitative measurement when assessing the parameters of cardiac function. Also, additional studies are needed to consider the relation between the baseline risk profile of the patients and their final outcomes and account for such an important parameter when measuring patient survival.

\section{CONCLUSIONS}

We have concluded that the reversibility of IMR is dependant on the reduction in the underlying ischemia. However, this is true for viable ischemic myocardium in which reversal of blood flow will result in improved ventricular function and wall motion. The status of viability and its effect on the early reversibility of moderate IMR, although it can be predicted by DSE, the long-term results could be misleading.

\section{References}

1. LaPar DJ, Kron IL. Should all ischemic mitral regurgitation be repaired? When should we replace? Curr Opin Cardiol. 2011;26:113-7.

2. Lamas GA, Mitchell GF, Flaker GC, Smith SC Jr, Gersh BJ, Basta L, et al. Clinical significance of mitral regurgitation after acute myocardial infarction: Survival and Ventricular Enlargement Investigators. Circulation. 1997;96: 827-33.

3. Tcheng JE, Jackman JD Jr, Nelson CL, Gardner LH, Smith LR, Rankin JS, et al. Outcome of patients sustaining acute ischemic mitral regurgitation during myocardial infarction. Ann Intern Med. 1992;117:18-24.

4. Hickey MS, Smith LR, Muhlbaier LH, Harrell FE Jr, Reves JG, Hinohara T, et al. Current prognosis of ischemic mitral regurgitation: implications for future management. Circulation. 1988;78(3 Pt 2):I51-9.

5. Badiwala MV, Verma S, Rao V. Surgical management of ischemic mitral regurgitation. Circulation. 2009;120:1287-93.

6. Aronson D, Goldsher N, Zukermann R, Kapeliovich M, Lessick J, Mutlak D, et al. Ischemic mitral regurgitation and risk of heart failure after myocardial infarction. Arch Intern Med. 2006;166:2362-8.

7. Grigioni F, Enriquez-Sarano M, Zehr KJ, Bailey KR, Tajik AJ. Ischemic mitral regurgitation: long-term outcome and prognostic implications with quantitative Doppler assessment. Circulation. 2001;103:1759-64.

8. Nkomo VT, Gardin JM, Skelton TN, Gottdiener JS, Scott CG, EnriquezSarano M. Burden of valvular heart diseases: a population-based study. Lancet. 2006:368:1005-11.

9. Mesana T. Ischemic mitral regurgitation: the challenge goes on. Curr Opin Cardiol. 2012;27:108-10.

10. Mihaljevic T, Gillinov AM, Sabik JF III. Functional ischemic mitral regurgitation: myocardial viability as a predictor of postoperative outcome after isolated coronary artery bypass grafting. Circulation. 2009;120:1459-61.

11. Aklog L, Filsoufi F, Flores KQ, Chen RH, Cohn LH, Nathan NS, et al. Does coronary artery bypass grafting alone correct moderate ischemic mitral regurgitation? Circulation. 2001;104(12 suppl 1):I68-75.

12. Gillinov AM, Wierup PN, Blackstone EH, Bishay ES, Cosgrove DM, White J, et al. Is repair preferable to replacement for ischemic mitral regurgitation? J Thorac Cardiovasc Surg. 2001;122:1125-41.

13. Lim E, Ali ZA, Barlow CW, Hosseinpour AR, Wisbey C, Charman SC, et al. Determinants and assessment of regurgitation after mitral valve repair. $J$ Thorac Cardiovasc Surg. 2002;124:911-7.

14. Hong JM, Cartier R, Pellerin M, Demers P, Bouchard D, Couture P. Long-term influence of mild or moderate ischemic mitral regurgitation after off-pump coronary artery bypass surgery. Can J Cardiol. 2010;26:203-7.

15. Adams DH, Filsoufi F, Aklog L. Surgical treatment of the ischemic mitral valve. J Heart Valve Dis. 2002;11(suppl 1):S21-5.

16. Grossi EA, Goldberg JD, LaPietra A, Ye X, Zakow P, Sussman M, et al. Ischemic mitral valve reconstruction and replacement: comparison of long-term survival and complications. J Thorac Cardiovasc Surg. 2001;122:1107-24. 
17. Filsoufi F, Salzberg SP, Adams DH. Current management of ischemic mitral regurgitation. Mt Sinai J Med. 2005;72:105-15.

18. Fattouch K, Guccione F, Sampognaro R, Panzarella G, Corrado E, Navarra E, et al. POINT: efficacy of adding mitral valve restrictive annuloplasty to coronary artery bypass grafting in patients with moderate ischemic mitral valve regurgitation: a randomized trial. J Thorac Cardiovasc Surg. 2009; 138:278-85.

19. Akins CW, Hilgenberg AD, Buckley MJ, Vlahakes GJ, Torchiana DF, Daggett WM, et al. Mitral valve reconstruction versus replacement for degenerative or ischemic mitral regurgitation. Ann Thorac Surg. 1994;58: 668-75; discussion 75-6.

20. Kay GL, Kay JH, Zubiate P, Yokoyama T, Mendez M. Mitral valve repair for mitral regurgitation secondary to coronary artery disease. Circulation. 1986; 74(3 Pt 2):I88-98.

21. Rankin JS, Hickey MS, Smith LR, Debruijn NP, Clements FM, Muhlbaier LH, et al. Current management of mitral valve incompetence associated with coronary artery disease. J Card Surg. 1989;4:25-42.

22. Cohn LH, Allred EN, Cohn LA, Austin JC, Sabik J, DiSesa VJ, et al. Early and late risk of mitral valve replacement: a 12 year concomitant comparison of the porcine bioprosthetic and prosthetic disc mitral valves. J Thorac Cardiovasc Surg. 1985;90:872-81.

23. Ngaage DL, Daly RC, Rosales G, Sundt TM III, Dearani JA, Mullany CJ, et al. Mitral regurgitation surgery in heart failure due to ischemic cardiomyopathy: a 24-year experience. J Heart Valve Dis. 2008;17:251-9; discussion 259-60.

24. Michelena HI, Bichara VM, Margaryan E, Forde I, Topilsky Y, Suri R, et al. Progress in the treatment of severe mitral regurgitation. Rev Esp Cardiol. 2010;63:820-31.

25. Gelsomino S, Lorusso R, De Cicco G, Capecchi I, Rostagno C, Caciolli S, et al. Five-year echocardiographic results of combined undersized mitral ring annuloplasty and coronary artery bypass grafting for chronic ischaemic mitral regurgitation. Eur Heart J. 2008;29:231-40.

26. Roshanali F, Mandegar MH, Yousefnia MA, Alaeddini F, Wann S. Low-dose dobutamine stress echocardiography to predict reversibility of mitral regurgitation with CABG. Echocardiography. 2006;23:31-7.
27. Agricola E, Oppizzi M, Pisani M, Meris A, Maisano F, Margonato A Ischemic mitral regurgitation: mechanisms and echocardiographic classification. Eur J Echocardiogr. 2008;9:207-21.

28. Gelsomino S, Lorusso R, Caciolli S, Capecchi I, Rostagno C, Chioccioli M, et al Insights on left ventricular and valvular mechanisms of recurrent ischemic mitral regurgitation after restrictive annuloplasty and coronary artery bypass grafting. J Thorac Cardiovasc Surg. 2008;136:507-18.

29. Hung J, Papakostas L, Tahta SA, Hardy BG, Bollen BA, Duran CM, et al. Mechanism of recurrent ischemic mitral regurgitation after annuloplasty: continued LV remodeling as a moving target. Circulation. 2004;110(11 suppl 1):II85-90.

30. Zhu F, Otsuji Y, Yotsumoto G, Yuasa T, Ueno T, Yu B, et al. Mechanism of persis tent ischemic mitral regurgitation after annuloplasty: importance of augmented posterior mitral leaflet tethering. Circulation. 2005;112(9 suppl):I396-401.

31. Miller DC. Ischemic mitral regurgitation redux - to repair or to replace? J Thorac Cardiovasc Surg. 2001;122:1059-62.

32. Milano CA, Daneshmand MA, Rankin JS, Honeycutt E, Williams ML, Swaminathan M, et al. Survival prognosis and surgical management of ischemic mitral regurgitation. Ann Thorac Surg. 2008;86:735-44.

33. Gorman RC, Gorman JH III. Why should we repair ischemic mitral regurgitation? Ann Thorac Surg. 2006;81:785-6.

34. Glower DD, Tuttle RH, Shaw LK, Orozco RE, Rankin JS. Patient surviva characteristics after routine mitral valve repair for ischemic mitral regurgitation. J Thorac Cardiovasc Surg. 2005;129:860-8.

35. Agricola E, Oppizzi M, Pisani M, Maisano F, Margonato A. Accuracy of real-time 3D echocardiography in the evaluation of functional anatomy of mitral regurgitation. Int J Cardiol. 2008;127:342-9.

36. Czer LS, Maurer G, Bolger AF, De Robertis M, Resser KJ, Kass RM, et al Intraoperative evaluation of mitral regurgitation by Doppler color flow mapping. Circulation. 1987;76(3 Pt 2):III108-16.

37. Sheikh KH, Bengtson JR, Rankin JS, de Bruijn NP, Kisslo J. Intraoperative transesophageal Doppler color flow imaging used to guide patient selection and operative treatment of ischemic mitral regurgitation. Circulation. 1991;84:594-604.

38. Ray S. The echocardiographic assessment of functional mitral regurgitation. Eur J Echocardiogr. 2010;11:111-7. 